\title{
A SEGUNDA GERAÇÃO DE LATINO-AMERICANOS NA CIDADE DE SÃO PAULO: A QUESTÃO DO IDIOMA
}

\author{
Gabriela Camargo de Oliveira*
}

\begin{abstract}
Embora São Paulo receba imigrantes provenientes de todo o mundo, a partir principalmente da década de 1970 podemos observar um aumento na entrada de imigrantes latino-americanos, especialmente bolivianos, paraguaios e peruanos. Os imigrantes latino-americanos têm construído suas vidas na cidade, estabelecendo residência, constituindo famílias e tendo filhos em São Paulo. Filhos estes que levantam a questão das gerações, sobretudo da segunda geração, que pode ser definida como a geração de filhos dos imigrantes adultos, que nasceram ou chegaram ainda novos ao país receptor. Compreender como a segunda geração tem se inserido na cidade e que relações mantêm com a comunidade local é fundamental para entender os efeitos da imigração para a sociedade. Portanto, este estudo busca explanar como vive a segunda geração latino-americana em São Paulo e suas experiências na cidade, destacando a questão do idioma.
\end{abstract}

Palavras chave: segunda geração, migração internacional, idioma.

\section{Presença latino-americana em São Paulo: 1940-2010}

A "nova" imigração de latino-americanos em São Paulo teve seu começo a partir da década de 1950, com a entrada de estudantes bolivianos e peruanos que vieram se especializar no país, por meio de acordos bilaterais entre o Brasil e esses países. De acordo com Silva, a partir de então, nas décadas de 1960 e, principalmente, a partir da década de 1970, a imigração intra-regional começou a se intensificar tanto por razões políticas quanto por razões econômicas.

\footnotetext{
Doutoranda em Demografia, Núcleo de Estudos de População/NEPO, Universidade Estadual de Campinas. Bragança Paulista - SP/Brasil.

1 SILVA, Sidney A. Faces da latinidade: hispano-americanos em São Paulo.
} 
Essa mudança no fluxo imigratório pode ser atribuída, entre outras coisas, à presença maciça de regimes militares na região e ao bom desenvolvimento da economia brasileira em relação aos outros países da América Latina naquele período ${ }^{2}$. Na década de 1980, a recessão econômica e pressão inflacionária fizeram parte do cenário econômico de grande parte dos países da região, que assistiram o índice de desemprego e pobreza aumentar de forma brutal.

Esse panorama, dentre outros fatores, contribuiu para incrementar as históricas imigrações latino-americanas, que até então estavam bem mais circunscritas às áreas de fronteira. O país passou, então, a fazer parte dos movimentos imigratórios regionais na América Latina ${ }^{3}$.

Segundo Patarra ${ }^{4}$, os fluxos imigratórios latino-americanos se destinaram, principalmente, para duas áreas: as regiões de fronteira e as regiões metropolitanas, em especial São Paulo e Rio de Janeiro. Nessa etapa, esses imigrantes vieram, em sua maioria, em busca de trabalhos que não exigissem muita qualificação ou documentação.

Ressalte-se que, embora, a cidade de São Paulo continue a se projetar como o polo da imigração internacional no país, recebendo imigrantes provenientes do mundo inteiro, os volumes da imigração com origem na América Latina vêm se destacando dentre os demais. O maior fluxo até 1990 foi de argentinos, chilenos e uruguaios. A partir de então até os dias de hoje pode-se observar uma maior entrada de bolivianos, paraguaios e peruanos, como podemos observar na Tabela 1 abaixo. Segundo dados do Censo Demográfico IBGE de 2010, na cidade de São Paulo residiam 21.680 bolivianos, 4.699 argentinos, 3.864 chilenos, 3.170 paraguaios, 2.949 peruanos e 1.475 uruguaios.

A maior parte dos imigrantes latino-americanos em São Paulo veio com o objetivo de trabalhar nos ramos de confecções, comércio e serviços ${ }^{5}$. O ramo da costura se tornou o principal entre os latino-americanos devido ao processo de substituição de mão-de-obra coreana pelos bolivianos e, mais tarde, pelos demais sul-americanos ${ }^{6}$.

2 Ibidem.

3 PATARRA, Neide Lopes e BAENINGER, Rosana. Mobilidade espacial da população no Mercosul: metrópoles e fronteiras.

4 PATARRA, Neide. Migrações internacionais e integração econômica no cone Sul: notas para discussão.

5 SILVA, op. cit.

6 FREITAS, Patrícia Tavares de. Imigração e experiência social: o circuito de subcontratação transnacional de força-de-trabalho boliviana para o abastecimento de oficinas de costura na cidade de São Paulo. 


\section{TABELA 1}

País de nascimento dos Imigrantes no Estado de São Paulo

Países selecionados da América Latina, 1940 a 2010

\begin{tabular}{ccccccc}
\hline Período & Argentina & Bolívia & Chile & Paraguai & Peru & Uruguai \\
\hline & & & & & & \\
1940 & 7.121 & 81 & 201 & 572 & 80 & 825 \\
1950 & 6.775 & 176 & 225 & 951 & 109 & 994 \\
1960 & 7.597 & 1.516 & 626 & 1.625 & 355 & 1.332 \\
1970 & 7.998 & 3.111 & 817 & 2.203 & 505 & 1.884 \\
1980 & 11.130 & 4.322 & 11.163 & 2.753 & 886 & 3.783 \\
1991 & 10.743 & 6.462 & 13.034 & 3.299 & 1.651 & 3.964 \\
2000 & 9.736 & 10.222 & 10.947 & 4.143 & 2.926 & 3.914 \\
2010 & 8.566 & 27.754 & 8.879 & 6.032 & 4.868 & 3.041 \\
\hline
\end{tabular}

Apesar do crescente aumento da imigração latino-americana para São Paulo, não temos ainda hoje um número consolidado sobre o volume do fluxo, podendo apenas estimar o tamanho desse contingente a partir da comparação entre os números oficias e extraoficiais. Entretanto, independente das diferenças entre os números oficiais e os estimados, é fato que a comunidade latino-americana na cidade de São Paulo é grande e vem crescendo cada vez mais, demonstrando um movimento imigratório de fluxo constante. Essa comunidade vem se estabelecendo na cidade ao longo dos últimos 40 nos e atualmente é presença marcante nos bairros centrais de São Paulo.

A nova face do fenômeno imigratório internacional em São Paulo - dada a temporalidade de seu fluxo - já se revela na permanência dos imigrantes latino-americanos, que têm construído suas vidas na cidade, permanecendo, constituindo famílias e tendo filhos na metrópole. Nesse contexto, emerge a questão da segunda geração de imigrantes latino-americanos na cidade.

\section{A segunda geração: definições conceituais}

A segunda geração pode ser definida como a geração de filhos dos imigrantes adultos, que nasceram ou chegaram ainda novos ao país receptor. Conforme definido por Waters, Kasinitz, Mollenkopf, “(...) A segunda geração e a geração 1.5 - gerações imigrantes... ou seja, pessoas cujos pais eram imigrantes, mas que nasceram ou foram substancialmente criadas nos Estados Unidos" ${ }^{\prime 7}$.

Tradução livre do trecho: "(...) second- and '1.5' - generation immigrants... that is, people whose parents were immigrants but who themselves were born or substantially raised in United States" (KASINITZ, Philip; MOLLENKOPF, John H.; WATERS, Mary C. Worlds of the second generation, p. 1) . 
Logo, a segunda geração é constituída por crianças que nasceram no país receptor e tinham ao menos um dos pais de origem estrangeira, enquanto a geração 1.5 são as crianças que nasceram no país de origem e migraram com seus pais, realizando parte de sua socialização no país de destino, enquanto crianças ou adolescentes.

Portes $^{8}$, no seu estudo sobre imigrantes latino-americanos nos Estados Unidos distinguiu três categorias: 1) as "crianças imigrantes", 2) as "crianças de imigrantes" e 3) "crianças nativas":

(...) três categorias distintas: crianças imigrantes, crianças de imigrantes e crianças nativas de pais nativos. A primeira categoria inclui jovens que nasceram no exterior e vieram para os Estados Unidos após a infância para serem criados aqui. A segunda inclui as crianças nascidas nos Estados Unidos de pais imigrantes e as crianças nascidas no exterior mas que vieram ainda muito novas (algumas vezes chamadas de geração 1.5). A terceira categoria, crianças nativas de pais nativos, representa a vasta maioria do total e dos adolescentes ${ }^{9}$.

Portes, Halles e Fernandez-Kelly ${ }^{10}$ incluem a segunda geração em suas pesquisas uma vez que os estudos sobre a segunda geração de imigrantes seriam tão importantes quantos os de primeira geração, dado que os efeitos de longo prazo da imigração numa sociedade seriam determinados mais pela segunda geração do que pela primeira.

O motivo que nos levou a voltar nossa atenção para os filhos foi a constatação de que os efeitos de longo prazo da imigração na sociedade norte-americana seriam determinados menos pela primeira do que pela segunda geração ${ }^{11}$.

Para esses autores, os imigrantes de primeira geração seriam flutuantes, ora no país receptor ora no país de origem, estariam na sociedade, mas não fariam parte dela; já os filhos desses imigrantes estariam para ficar no país, como cidadãos. Além disso, seria a segunda geração a determinar a manutenção ou não de práticas culturais originárias. Assim, os autores enfatizam que estudar

8 PORTES, Alejandro. The New Second Generation.

9 Tradução livre da autora: “(...) three distinct categories: immigrant children, children of immigrants, and native-born children of native parentage. The first category includes youth who are born abroad and come to the United States after early infancy to be raised here. The second includes native-born children of immigrant parents and children born abroad who came at a very early age (sometimes called the 1.5 generation). The third, native-born children of native parentage, represents the vast majority of both the total and adolescent populations" (Ibidem, p. ix).

${ }^{10}$ PORTES, Alejandro; HALLEY, William; FERNANDEZ-KELLY, Patricia. Filhos de imigrantes nos Estados Unidos.

11 Ibidem, p. 13. 
a segunda geração de imigrantes é tão importante quanto estudar a primeira geração. Ademais, seria preciso compreender como a segunda geração tem se inserido na sociedade receptora e que relações mantêm com a comunidade local para entender os efeitos da imigração para a sociedade.

Imigrantes de primeira geração sempre foram um grupo muito flutuante, hoje aqui e amanhã já de partida, na sociedade, porém não ainda parte dela. Em contraste, seus filhos nascidos e criados nos Estados Unidos estão nesse país, sem a menor dúvida, para ficar e, como cidadãos, estão inteiramente habilitados a ter "voz" no sistema político norte-americano (no sentido do termo utilizado em Hirschman [1970]). Portanto, o decurso de sua adaptação determinará, mais do que outros fatores, no longo prazo, o destino dos grupos étnicos gerado pelos imigrantes de hoje ${ }^{12}$.

Segundo Portes et alii ${ }^{13}$, seria preciso entender o processo de assimilação da segunda geração de imigrantes na sociedade receptora. Para os autores, no caso dos EUA a hipótese da assimilação uniforme não se aplicaria totalmente à "nova segunda geração"14, uma vez que a assimilação não estaria ocorrendo nos mesmos moldes da assimilação das correntes imigratórias anteriores. Logo, teria havido mudanças nas formas de assimilação: desde os primeiros estudos sobre assimilação de imigrantes e ao contrário do que aconteceu com a segunda geração de imigrantes do pós-Primeira e Segunda Guerra Mundial, a "nova segunda geração" não estaria sendo assimilada ao mainstream de forma uniforme como foi a segunda geração do fluxo imigratório europeu.

(...) a imagem de uma trajetória de assimilação uniforme não dava conta do que efetivamente estava ocorrendo. Em vez disso, o processo havia se tornado segmentado em vários percursos distintos, alguns levando a trajetórias ascendentes, outros, a trajetórias descendentes ${ }^{15}$.

Para os autores, esse fato se deve a uma variedade de fatores na sociedade que são diferentes hoje do que eram anteriormente e às diferenças étnico-culturais dos novos imigrantes. Fatores como o contexto social da sociedade receptora, composição familiar, preconceito, barreiras educacionais, características fenotípicas, políticas públicas para imigrantes e outros, fazem com que a assimilação ocorra de forma "segmentada".

\footnotetext{
12 Ibidem.

13 Ibidem.

14 O termo "nova segunda geração" se refere à segunda geração do fluxo migratório pós-1965 para os Estados Unidos, que é predominantemente latino e asiático. Diferenciando-se do termo segunda geração, muitas vezes associado ao fluxo imigratório europeu do começo do século 20 para os Estados Unidos.

15 Ibidem, p. 14.
} 
A "assimilação segmentada"16 pode ser definida como assimilação em alguns setores específicos da sociedade, como em setores minoritários e não em sua totalidade: “(...) Assimilação segmentada descreve os vários resultados de diferentes grupos de jovens de segunda geração e argumenta que o modo de incorporação da primeira geração é responsável pelos diferentes acessos da segunda geração às oportunidades e redes sociais"17.

Para Portes e Zhou ${ }^{18}$ a "assimilação segmentada" retrata as diferentes formas de inserção na sociedade de recepção.

Ao em vez da uniformidade relativa da sociedade, que ditam os caminhos comuns de integração por meio dos costumes e preconceitos, hoje em dia nós observamos diversas formas de adaptação. Uma delas replica o retrato honorável do crescimento da aculturação e da paralela integração dentro da classe média branca; a segunda leva diretamente para o caminho oposto em direção à pobreza permanente e assimilação nos segmentos minoritários da sociedade; ainda, a terceira associa rápido avanço econômico com preservação deliberada dos valores e laços de solidariedade da comunidade imigrante ${ }^{19}$.

Segundo os autores, a "nova segunda geração" estaria vivendo um conflito de adaptação tanto de ordem cultural como social; entre a pressão dos pais para que mantenham laços fortes com a comunidade étnica e os desafios de ingressar num mundo não-familiar e frequentemente hostil. Segundo os autores, as condições econômicas e sociais na época dos fluxos imigratórios do pós-Primeira e Segunda Guerra Mundial eram bem diferentes das confrontadas pelos imigrantes atuais. Esse processo, nos EUA, teria deixado para os novos imigrantes uma lacuna entre as atividades de baixa remuneração geralmente exercida por eles e as atividades profissionais bem remuneradas que requerem ensino superior, geralmente exercida pelas elites nativas ${ }^{20}$.

Deste modo, hoje, os novos imigrantes teriam menos chances de mobilidade na sociedade receptora dos que tinham os imigrantes dos

\footnotetext{
${ }^{16}$ KASINITZ, MOLLENKOPF, WATERS, op. cit.

17 Tradução livre da autora: “(...) segmented assimilation describes the various outcomes of different groups of second-generation youth and argues that the mode of incorporation for the first generation gives the second generation access to different types of opportunities and social networks" (ibidem, p. 7).

18 PORTES, Alejandro e ZHOU, Min. The new second generation: segmented assimilation and its variants.

19 Tradução livre da autora: "Instead of a relatively uniform mainstream whose mores and prejudice dictate a common path of integration, we observe today several distinct forms of adaptation. One of the replicates the time-honored portrayal of growing acculturation and parallel integration into the white middle-class; a second leads straight in the opposite direction to permanent poverty and assimilation into the underclass; still a third associates rapid economic advancement with deliberate preservation of immigrant community's values and tight solidarity" (ibidem, p. 90).

20 Ibidem.
} 
fluxos anteriores. Esse fator, associado a outros, como preconceito e falta de oportunidades educacionais, poderiam estar resultando em uma "assimilação descendente", ou seja, nos grupos minoritários do mainstream, dentro das subculturas, ao contrário do que ocorreu com os descendentes dos imigrantes europeus que tiveram uma "assimilação ascendente". Mas segundo Portes e $Z_{h o u}{ }^{21}$, na realidade, a situação ainda não se tornou tão polarizada, logo seria possível observar a assimilação em diversos segmentos da sociedade. Mas mesmo assim seria necessário compreender as trajetórias que resultam em assimilações tão distintas, compreender como e o porquê dessas distintas assimilações para entender os resultados da integração da segunda geração na sociedade de acolhimento.

No Brasil, também temos uma "nova segunda geração", ou seja, os descendentes da nova corrente imigratória recente para o país. Mas apesar de vários estudos ${ }^{22}$ já terem sido realizados sobre a primeira geração desses imigrantes, pouco se conhece sobre a realidade da segunda geração. Contudo, conhecer a segunda geração de imigrantes se faz importante para a compreensão do fenômeno migratório em suas diversas faces e suas consequências a longo prazo para a sociedade brasileira. Para tal, esse estudo faz uso de duas metodologias, uma quantitativa e outra qualitativa. Para observar de forma quantitativa o grupo em questão, foram analisadas as informações dos microdados do Censo Demográfico 2000, a partir da reconstituição domiciliar e da identificação dos indivíduos. Com objetivo de aprofundar o conhecimento do grupo também foram realizadas entrevistas - a partir de questionário semi-estruturado - com adolescentes da segunda geração de latino-americanos, que frequentavam a escola e estavam matriculados entre o nono ano do ensino fundamental e o terceiro ano do ensino médio. Além disso, também foram realizadas entrevistas em profundidade com os pais de alguns dos alunos pesquisados.

\section{Segunda geração de latino-americanos: o caso paulista}

O fluxo imigratório latino-americano para São Paulo data de pelo menos 40 anos atrás e um contingente expressivo de famílias imigrantes se formou na cidade de São Paulo, fato associado ao próprio fenômeno migratório em si, ao processo de reunificação familiar e a formação de novas famílias. Famílias essas compostas de várias gerações, incluindo a geração 1.5 e a segunda geração.

Segundo estudos recente ${ }^{23}$ a segunda geração da corrente imigratória de latino-americanos para o país é presença marcante na cidade de São

\footnotetext{
${ }^{21}$ Ibidem.

22 SILVA, op. cit.; FREITAS, op. cit; PAIVA, Odair C. A imigração de latino-americanos para São Paulo (Brasil): dois tempos de uma mesma história.

${ }^{23}$ OLIVEIRA, Gabriela C. A segunda geração de latino-americanos na Região Metropolitana de São
} 
Paulo, principalmente nas regiões centrais e em algumas escolas públicas que chegam a ter até $50 \%$ dos seus alunos de origem estrangeira.

Apesar disso, pouco se sabe sobre essas crianças e adolescentes, tanto em termos quantitativos como em termos qualitativos devido à indocumentação característica do fluxo. Fato ainda mais agravado uma vez que parte considerável da segunda geração é brasileira e, portanto, considerada nas fontes oficiais como tal, mascarando a origem familiar estrangeira. No entanto, a formação da segunda geração de imigrantes latino-americanos pode ser observada nos microdados do Censo Demográfico 2010, conforme gráfico 1 a seguir ${ }^{24}$.

\section{GRÁFICO 1}

\section{Segunda geração de imigrantes latino-americanos - RMSP 2010}

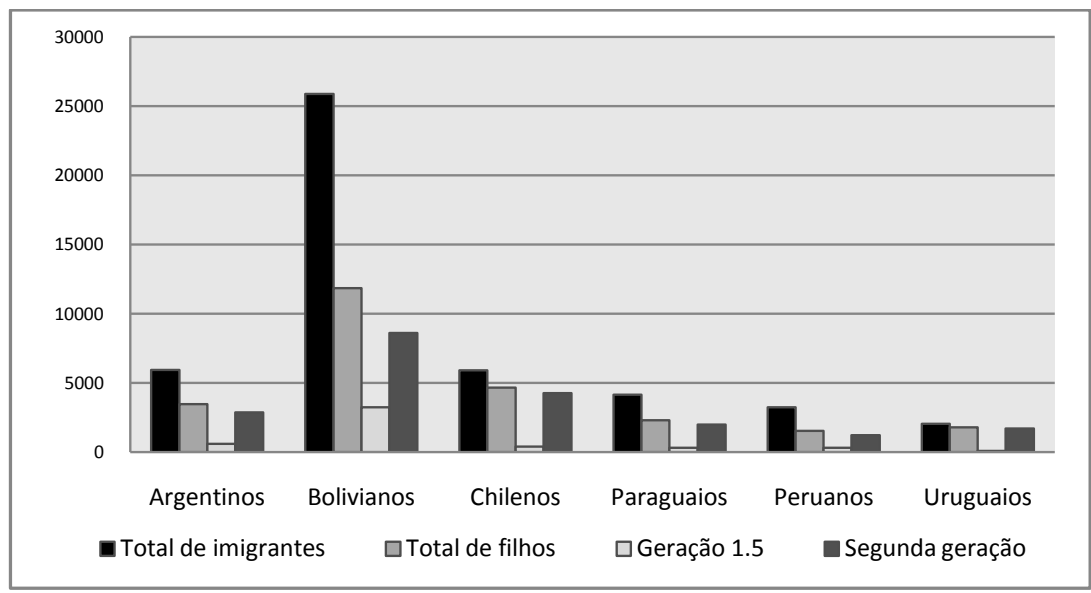

Fonte: Fundação IBGE, Censo Demográfico de 2010 - Amostra expandida. Tabulações especiais.

Analisando o gráfico é possível notar que a segunda geração compunha a maior parte dos filhos presentes em domicílios de origem imigrante. No caso da imigração argentina foi possível observar que o total de filhos somou 3.467 indivíduos (2.865 da segunda geração e 602 da geração 1.5). Já no caso da imigração de bolivianos foi possível notar um total de filhos foi de 11.853 (8.607 da segunda geração e 3.246 da geração 1.5), enquanto para os domicílios de origem chilena observamos a presença de 4.671 filhos (397 da geração 1.5 e 4.274 da segunda geração). No caso dos paraguaios

Paulo; MAGALHÃES, Giovanna Mode. Fronteiras do direito humano à educação: um estudo sobre imigrantes bolivianos nas escolas públicas de São Paulo.

${ }^{24}$ Com objetivo de observar a presença da segunda geração de latino-americanos na cidade de São Paulo, a metodologia adotada foi a análise dos microdados da amostra expandida do Censo Demográfico 2010. Para análise dessa segunda geração foi realizada a reconstituição domiciliar desses imigrantes com o objetivo de captar, a partir do Censo Demográfico de 2010, as famílias com presenças de filhos nascidos no país estrangeiro e filhos nascidos no Brasil. 
somaram-se 2.295 filhos (301 da geração 1.5 e 1.994 da segunda geração), enquanto para os domicílios peruanos foram registrados 1.535 filhos (1.222 da segunda geração e 313 da geração 1.5). Finalmente, no caso dos uruguaios o número de filhos foi de 1.790 (95 da geração 1.5 e 1.695 da segunda geração).

Logo, diante desse cenário podemos observar, ao menos de forma ilustrativa, a importância quantitativa da segunda geração no fluxo imigratório para São Paulo. Porém como captar, observar e compreender de forma mais aprofundada a segunda geração na cidade de São Paulo? Com esse objetivo foi escolhida a escola como espaço privilegiado de contato e observação da segunda geração. Essa escolha se deve a três motivos: o primeiro decorrente da constatação da numerosa presença de estrangeiros no sistema de ensino, tanto público como particular, principalmente em determinadas regiões da cidade de São Paulo, que podem ser observadas a partir das informações do Censo Escolar 2010. O segundo, porque a escola é sem dúvida o local, além da casa, no qual as crianças e adolescentes passam a maior parte de seu tempo. Terceiro, porque a escola ainda é hoje um importante espaço de socialização de crianças e jovens ${ }^{25}$.

Portanto, diante do crescente aumento de matrículas de alunos estrangeiros no sistema de ensino se faz necessário analisar de forma mais aprofundada a presença desses estrangeiros nas escolas paulistas. Com esse objetivo foram realizadas entrevistas qualitativas com a segunda geração e a geração 1.5 de alunos matriculados entre o nono ano do Ensino Fundamental e o terceiro ano do Ensino Médio na escola alvo da pesquisa ${ }^{26}$.

${ }^{25}$ Berger e Luckmann define o processo de socialização “(...) como a ampla e consistente introdução de um indivíduo no mundo objetivo de uma sociedade ou de um setor dela. A socialização primária é a primeira socialização que o indivíduo experimenta na infância, em virtude do qual se torna membro da sociedade. A socialização secundária é qualquer processo subsequente que introduz um indivíduo já socializado em novos setores do mundo objetivo de sua sociedade" (BERGER, Peter e LUCKMANN, Thomas. A construção social da realidade, p. 169).

${ }^{26}$ Pesquisa realizada no primeiro semestre de 2011, em uma escola estadual localizado no bairro Campos Elíseos, na cidade de São Paulo/SP. Em relação à forma de pesquisa escolhida para a segunda geração foi a entrevista qualitativa a partir de um questionário semiestruturado fechado. Tal escolha se deveu aos seguintes motivos: o primeiro deles está relacionado ao objetivo de alinhar a metodologia de pesquisa com a teoria escolhida para a compreensão da segunda geração seguindo, portanto, os mesmos caminhos de pesquisa inicialmente propostos por Portes (op. cit.); o segundo motivo está relacionado ao tamanho do grupo a ser pesquisado, que impossibilitava a realização de entrevistas em profundidade com todos os indivíduos em questão. Para a realização da pesquisa foram aplicados 437 questionários na escola-alvo, nos alunos que cursavam entre a oitava série do Ensino Fundamental II e o terceiro ano do Ensino Médio, presentes nos dias da pesquisa. Dos 437 questionários aplicados 75 foram de segunda geração, ou seja, 17\% do total. Além disso, também foram realizadas entrevistas em profundidade com alguns pais desses alunos pesquisados. 
$\mathrm{Na}$ pesquisa diversos assuntos foram abordados, dentre eles questões sócio-demográficas e de identificação como local de nascimento, nacionalidade dos pais, idade, tempo de residência no Brasil e questões mais amplas e subjetivas como conhecimento da língua espanhola, frequência da utilização do espanhol, educação, trabalho, relações pessoais, identidade e discriminação, entre outras que já foram abordadas em artigos anteriores. E são precisamente as questões sobre conhecimento e habilidade na língua portuguesa e espanhola que esse artigo irá tratar.

\section{A segunda geração: caracterização e vivências}

Dentre os 75 alunos de segunda geração captados, 29 eram do sexo masculino e 46 eram do sexo feminino. Destes, 26 eram da segunda geração de fato, ou seja, nascidos no Brasil, e 49 eram da geração 1.5, nascidos no exterior. Sendo a geração 1.5 constituída, em ordem decrescente, de bolivianos, paraguaios e peruanos. No que diz respeito à idade da segunda geração, a maior parte dos entrevistados tinha entre 13 a 15 anos; fato esse que se deve principalmente ao grupo entrevistado em questão e à série que frequentavam, uma vez que a maior parte dos entrevistados frequentava o nono ano do Ensino Fundamental.

Dentre as muitas variáveis pesquisadas o idioma foi uma variável fundamental na pesquisa devido à sua importância no cotidiano desses jovens e à sua função social na interação com a sociedade. Segundo Portes e Rumbaut ${ }^{27}$, a manutenção do idioma de origem é fundamental entre os imigrantes, sendo dentre todos os legados transmitidos entre as gerações o mais importante. No entanto, seria o mais difícil legado a se transmitir devido a forças opostas, como a demanda da sociedade para que os imigrantes se assimilem linguisticamente.

No que concerne ao idioma falado pela segunda geração, entre o total dos entrevistados a maioria falava ou sabia falar a língua do país de origem dos pais, o espanhol. Fato que demonstra que a maior parte da segunda geração e da geração 1.5 de latino-americanos tem contato com o idioma de origem e afirma ter algum grau de conhecimento no mesmo. Embora não seja possível estabelecer se são indivíduos bilíngues ou apenas retém o conhecimento do idioma. Dentre os que responderam que falavam o idioma do país de origem, no caso o espanhol, foram registrados diversos graus de habilidade no idioma, conforme é possível observar no gráfico 2.

${ }_{27}$ PORTES, Alejandro e RUMBAUT, Rubén G. Legacies: the story of the immigrant second generation. 


\section{GRÁFICO 2}

Segunda geração de latino-americanos, segundo grau de habilidade no idioma de origem ${ }^{*}$ - São Paulo - 2011

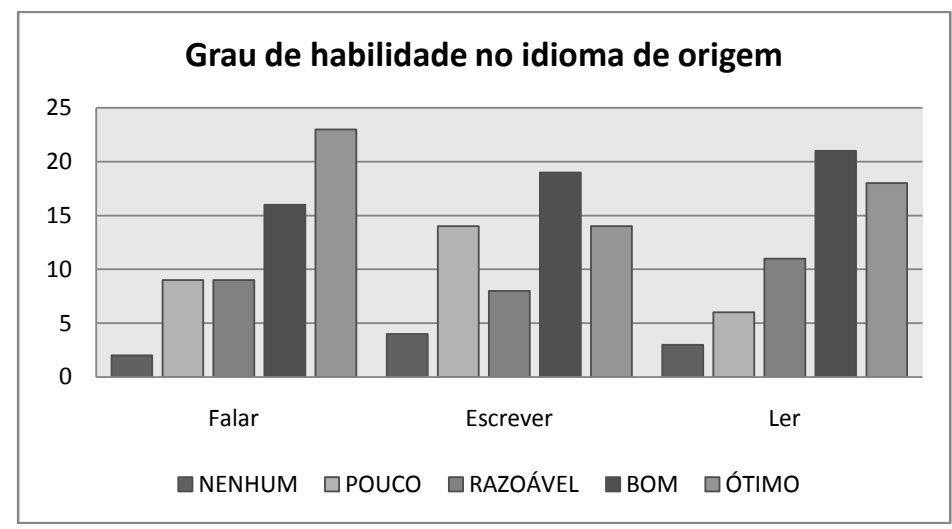

Fonte: Projeto temático “Observatório das Migrações em São Paulo/Segunda geração de latino-americanos em São Paulo". UNICAMP/NEPO/FAPESP/CNPq, 2011.

*Estudantes da rede pública de ensino entrevistados.

Em relação à capacidade de falar o idioma espanhol a maioria dos entrevistados relatou ter um nível bom ou ótimo, sendo minoria aqueles que tinham baixa habilidade no idioma. Já em relação à habilidade de escrever o cenário é similar ao anterior, ou seja, mais da metade afirmou ter uma capacidade de escrita boa ou ótima. No entanto, podemos observar que uma parcela considerável dos entrevistados afirmou ter um grau de habilidade de escrever baixo ou nenhum. Em relação à capacidade de ler no idioma de origem, assim como para o falar e o escrever, também a maior parte dos indivíduos afirmou ter uma boa ou ótima habilidade na leitura do espanhol. Demonstrando que a maior parte dos jovens pesquisados tinha não apenas algum grau de conhecimento do idioma, mas também alguma capacidade de se comunicar, escrever e ler. Fato resultante tanto da vivência da geração 1.5 antes de migrar para o Brasil, mas também da manutenção, ao menos parcial, da língua materna no Brasil. Manutenção essa, segundo Portes e Rumbaut, que é importante tanto em termos culturais como em termos práticos. Segundo os autores, perder a língua de origem seria como perder parte de si que está diretamente ligada com a identidade e a herança cultural. Além disso, a perda do idioma de origem poderia tornar a comunicação entre as gerações mais difícil, resultando na diminuição da autoridade dos pais ${ }^{28}$. No entanto, esse não parece ser o caso da segunda geração de latino-americanos pesquisada.

${ }^{28}$ Ibidem. 
Em relação à habilidade da geração 1.5 na língua portuguesa, foi possível observar que apenas poucos entrevistados afirmaram ter um baixo grau de habilidade para falar, escrever, ler e entender o português, conforme podemos observar no gráfico 3, pois a grande maioria informou ter um bom ou ótimo grau de habilidade. Esse resultado pode ser atribuído, a princípio, a dois fatores: o primeiro, o tempo de residência no Brasil, uma vez que os entrevistados que moram há mais tempo no país afirmaram ter maior conhecimento da língua; o segundo, a inserção dos mesmos na escola, que obrigatoriamente insere essas crianças e adolescentes num espaço monolíngue, forçando a ter contato diário com a língua portuguesa. Ademais, segundo Portes e Rumbaut ${ }^{29}$, existiria uma pressão social para que os estrangeiros assimilem o idioma nativo, tanto por razões instrumentais como por razões simbólicas. A assimilação linguística seria vista como um sinal de boa vontade dos imigrantes em buscar aceitação dentro do novo país, deixando a lealdade com o país de origem no passado. Por isso é considerada fundamental no processo de assimilação dos imigrantes.

\section{GRÁFICO 3}

\section{Segunda geração de latino-americanos, segundo grau de habilidade em Língua Portuguesa* - São Paulo 2011}

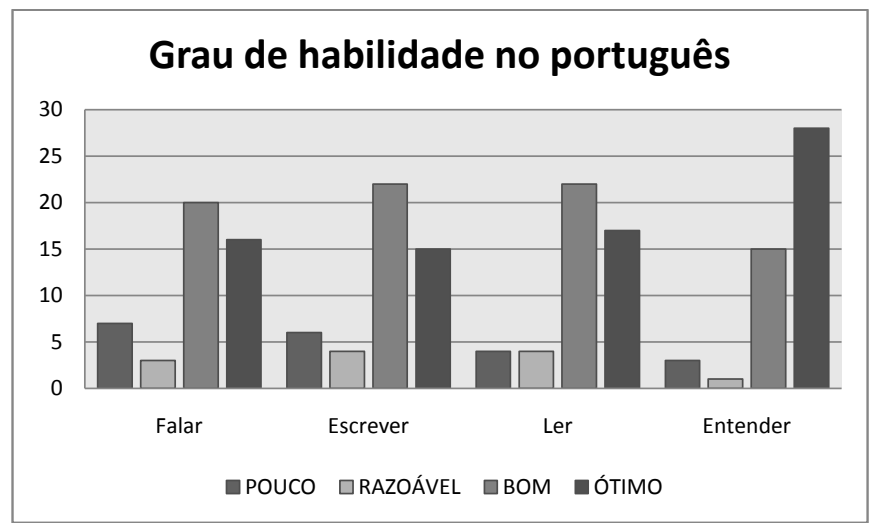

Fonte: Projeto temático "Observatório das Migrações em São Paulo/Segunda geração de latino-americanos em São Paulo". UNICAMP/NEPO/FAPESP/CNPq, 2011.

*Estudantes da rede pública de ensino entrevistados.

Quando questionados sobre o idioma mais falado em diversas ocasiões, os entrevistados afirmaram usar as duas línguas. No ambiente da casa, quase um terço dos entrevistados utiliza as duas línguas, enquanto um terço afirmou falar mais português e o outro terço mais espanhol. O que demonstra que

\footnotetext{
${ }^{29}$ Ibidem
} 
dentro de casa a maior parte dos entrevistados fala o idioma de origem em algum momento. Já quando questionados sobre qual idioma mais falavam no dia a dia, a maioria dos informantes afirmou falar mais o português, indicando, assim, que o idioma de origem é mais restrito às situações familiares como nas conversas entre pais e filhos: a maioria informou que seus pais conversam com eles em espanhol ou nas duas línguas enquanto os mesmos respondem, na maioria dos casos, mesclando o português e o espanhol e apenas um terço usa exclusivamente o português ao conversar com os pais.

O uso diferenciado dos idiomas e sua combinação ao falar foram ressaltados também nas entrevistas em profundidade realizadas com os pais desses adolescentes. Entre os entrevistados ${ }^{30}$, todos afirmaram conversar em espanhol com seus filhos, embora os mesmos respondessem em português. Como é possível observar nas falas a seguir, quando questionados sobre a língua que era falada em casa:

Eu falo espanhol. Eu nasci em La Paz, fui criado em La Paz e estudei em La Paz. Eu falo com minha esposa normalmente o espanhol, falo com meu filho em espanhol, pergunto em espanhol, porém ele responde em português. Quer dizer que ele entende o espanhol, mas responde em português. Bom por um lado, eu falo pra ele porque aqui com a gente você não fala em espanhol e ele responde que é porque fala errado, pronuncia errado, tudo bem, mas aqui estamos entre nós, pratica né.

Já outro entrevistado afirmou conversar nas duas línguas com os filhos, já que os filhos mais velhos falam espanhol enquanto o mais novo fala apenas português.

Eu falo os dois. É porque a G. sempre fala português para nós, às vezes ela não entende o que eu falo em castelhano então tenho que falar português. Ela fala: mãe, não entendi. Então tem que repetir em português. Mas ela só fala em português. As minhas duas outras filhas falam castelhano e português.

Outro entrevistado afirma não se preocupar com o fato dos filhos não falarem espanhol quando questionado sobre o assunto: "Não. Eu tenho canal da Bolívia, mas também não chama atenção. Tampouco nunca proibi não falar espanhol. Porque eles nunca conseguiram falar, eu falo mais espanhol com eles, mas eles não falam".

Isso demonstra como a língua do país de origem é presente no dia a dia dos adolescentes entrevistados, mesmo que tenham dificuldades em

\footnotetext{
${ }^{30}$ Foram realizadas entrevistas qualitativas em profundidade com alguns pais dos alunos pesquisados no mesmo período da realização da pesquisa na escola.
} 
comunicar-se na língua dos pais. Portanto, mesmo com as dificuldades linguísticas que os entrevistados enfrentam para se comunicar na língua dos pais, o espanhol ainda permanece como idioma fundamental entre o grupo em questão.

Para além da esfera da casa e da família, metade dos entrevistados relatou falar outro idioma além do português ao conversar com os amigos enquanto a outra metade afirmou falar apenas português. Quando perguntados sobre a frequência ao falar outro idioma além do português no dia a dia a maioria relatou falar cotidianamente outro idioma. Isso demonstra que esses adolescentes recorrem ao uso do idioma de origem em diversos momentos, ao menos no uso de algumas palavras, não só em casa, embora metade deles relate falar apenas português ao conversarem com amigos.

Portanto, foi possível observar certo grau de manutenção do idioma de origem, principalmente na esfera familiar. Manutenção essa que segundo Portes e Rumbaut ${ }^{31}$ pode ser considerada como positiva, se tornando uma habilidade a mais frente às crescentes demandas por força de trabalho com conhecimentos em mais de um idioma. No entanto, parte significativa da segunda geração não tinha habilidade para falar o espanhol ou seu conhecimento era demasiado restrito para que de fato possam ser considerados bilíngues. Logo a grande maioria dos entrevistados pode ser considerada como linguisticamente assimilada à sociedade brasileira, mesmo dentre aqueles que chegaram a menos de um ano no Brasil, fato resultante, provavelmente, da rápida assimilação linguística dentro do ambiente escolar.

\section{Considerações finais}

Dentre as muitas questões levantadas no debate sobre a segunda geração de imigrantes, o idioma e seus usos foi o tema principal deste artigo. Conforme ressaltam Portes e Rumbaut ${ }^{32}$, a manutenção do idioma de origem é uma característica importante na vida dessas crianças e adolescentes, podendo impactar de maneira positiva ou negativa no processo de integração com a sociedade receptora. Conforme a análise dos resultados observados a partir da pesquisa qualitativa, foi possível observar que a segunda geração de latino-americanos pesquisada mantém o uso do idioma espanhol, embora o grau de habilidade seja bastante variado. Faz-se uso do mesmo diariamente e principalmente nas relações familiares, enquanto o uso do português se faz mais presente em outras ocasiões do dia a dia. Infelizmente não foi possível estabelecer se o grupo estudado era de fato bilíngue. No entanto,

\footnotetext{
31 Ibidem.

32 Ibidem.
} 
constatou-se que o idioma espanhol tem parte significativa da vida dos mesmos, principalmente na relação entre pais e filhos. Contudo, parece haver uma relação direta entre o tempo de residência no Brasil e a habilidade no idioma espanhol, ou seja, a diminuição da habilidade no idioma conforme o aumento do tempo de residência no Brasil. Cabe lembrar, ademais, que as análises ensejadas nesse artigo são apenas observações iniciais, sendo necessário aprofundar melhor o conhecimento tanto em relação à questão da manutenção do idioma de origem, quanto das outras questões que giram em torno do debate da segunda geração de imigrante.

Logo, esse artigo teve também como objetivo aprofundar a discussão sobre o tema da segunda geração de imigrantes e trazer elementos para pensar o grupo em questão e sua vivência e experiências na cidade de São Paulo. Para tal, usou do recorte a questão do idioma. Partiu-se do pressuposto que o entendimento da segunda geração se faz essencial para compreender o fluxo de latinos americanos para São Paulo e principalmente para o entendimento do fenômeno migratório em suas diversas faces, considerando que, para além dos impactos da primeira geração de latino-americanos em São Paulo, também devemos analisar a questão de um ponto de vista mais amplo, levando em considerações ambas as gerações.

Assim sendo, podemos perceber que ao restringirmos os estudos migratórios apenas às questões relacionadas às primeiras gerações empobrecemos o entendimento das comunidades migrantes e do fenômeno migratório em si. Além disso, deixamos de compreender como a segunda geração se relaciona com a sociedade de acolhimento, no caso a cidade de São Paulo. Relação essa que tem encontros e desencontros, passando entre a aceitação e a discriminação dos grupos imigrantes latino-americanos.

Entretanto, para entender essa relação muitos elementos precisam ser analisados. No caso da segunda geração latino-americana em São Paulo os elementos que mais se sobressaíram foram relacionados à questão da autoidetificação, da discriminação e do idioma. No entanto, as análises aqui apresentadas precisam ser mais aprofundadas para que possam ser feitas conclusões a respeito da assimilação da segunda geração, trazendo, portanto, por ora, apenas subsídios para começar a entender o processo.

Ademais, outro desafio se impõe: o grupo em questão ainda é novo, composto majoritariamente de crianças e adolescentes. Portanto, analisar sua assimilação não seria eficaz uma vez que a mesma ainda não se estabeleceu de fato na sociedade, não terminou seus estudos e ingressou no mercado de trabalho, não possibilitando observar seu processo assimilatório na sociedade brasileira. Além disso, o tempo de exposição dessas crianças 
e adolescente à sociedade brasileira ainda é pequeno e os processos de assimilação vivenciados e observados encontram-se apenas nas fases iniciais. Logo, podemos apenas buscar os elementos iniciais para entender esse processo e seus desafios.

Mas supondo que a maior parte dessas crianças não retorne ao país de origem, elas realizarão a maior parte de sua socialização no Brasil. Todavia, por se tratar de uma população de origem estrangeira, principalmente em relações as raízes culturais, embora a maior parte tenha nacionalidade brasileira, estas crianças e adolescentes poderão enfrentar problemas de inserção na sociedade brasileira e conflitos relacionados à sua autoidentificação. Desafios e conflitos esses que devem ser analisados para compreender como se dá a relação entre a segunda geração e a sociedade paulistana e brasileira. Portanto, vale ressaltar que ignorar a bagagem cultural da segunda geração classificando-os como brasileiros, em primeiro lugar, é negar seu direito à descendência cultural e nacional e, em segundo lugar, ignorar os desafios enfrentados por eles no dia a dia, na convivência com seus pares nacionais, como no caso da escola. Diante disso, faz-se imperativo compreender mais profundamente a segunda geração, tanto para melhor entender seu papel dentro do fenômeno migratório como seu papel na formação das comunidades estrangeiras em São Paulo.

No que tange a escola, é fato que essas crianças são presença marcante nas escolas do centro de São Paulo. Isto nos leva a pensar que a questão imigratória vai muito além de se compreender a inserção dos imigrantes em si, mas também a integração de seus descendentes brasileiros e bem como as consequências dessa imigração para a sociedade brasileira. Isto nos leva a pensar na necessidade de políticas educacionais que contemplem o devido aproveitamento dessas crianças no sistema escolar, minimizando conflitos e harmonizando as diferenças. No entanto, o objetivo desse trabalho foi mais no sentido de encontrar caminhos para entender o processo de assimilação da segunda geração e não compreender o processo de assimilação em si.

\section{Referências bibliográficas}

BAENINGER, Rosana (org.). Imigração boliviana no Brasil. Campinas: NEPO/ UNICAMP, 2012.

BAENINGER, Rosana; SIMAI, Szilvia. Discurso, negação e preconceito: bolivianos em São Paulo. In BAENINGER, Rosana (org.). Imigração boliviana no Brasil. Campinas: NEPO/UNICAMP, 2012.

BERGER, Peter; LUCKMANN, Thomas. A construção social da realidade. Petrópolis: Vozes, 2011. 
FREITAS, Patrícia Tavares de. Imigração e experiência social: o circuito de subcontratação transnacional de força-de-trabalho boliviana para o abastecimento de oficinas de costura na cidade de São Paulo. Tese de Doutorado. Dissertação de Mestrado, Departamento de Sociologia, IFCH, Universidade estadual de Campinas (Unicamp), Campinas, 2009.

KASINITZ, Philip; MOLLENKOPF, John H.; WATERS, Mary C.; HOLDAWAY, Jennifer. Inheriting the city: the children of immigrants come of age. New York: Russell Sage Foundation, 2008.

KASINITZ, Philip; MOLLENKOPF, John H.; WATERS, Mary C. Worlds of the second generation. In KASINITZ, Philip; MOLLENKOPF, John H.; WATERS, Mary C. Becoming New Yorkers: ethnographies of the new second generation. New York: Russell Sage Foundation, 2004.

MAGALHÃES, Giovanna Mode. Fronteiras do direito humano à educação: um estudo sobre imigrantes bolivianos nas escolas públicas de São Paulo. Dissertação de Mestrado. Programa de Pós-graduação em Relações Internacionais, USP, São Paulo, 2010.

MOLLENKOPF, John H.; WATERS, Mary C. Becoming New Yorkers: ethnographies of the new second generation. New York: Russell Sage Foundation, 2004.

OLIVEIRA, Gabriela Camargo de. A segunda geração de latino-americanos na Região Metropolitana de São Paulo. Dissertação de Mestrado. Programa de Pós-graduação em Demografia, IFCH/UNICAMP, Campinas, 2012.

. Efeitos indiretos da imigração: segunda geração de latino-americanos na cidade de São Paulo. In TEIXEIRA, P. Eduardo; COSTA BRAGA, Antonio M.; BAENINGER, Rosana. Migrações: implicações passadas, presentes e futuras. Marília: Cultura Acadêmica Editora, 2012.

. Crianças imigrantes na rede de ensino de São Paulo. In Anais do XXVIII Congresso Internacional da Associação Latino-americana de Sociologia ALAP, 2011.

PAIVA, Odair C. A imigração de latino-americanos para São Paulo (Brasil): dois tempos de uma mesma história. São Paulo: Pastoral do Imigrante, 2007.

PATARRA, Neide. Migrações internacionais e integração econômica no cone Sul: notas para discussão. In SALES, Teresa; SALLES, Maria do Rosário R. (orgs.). Políticas migratórias: América Latina, Brasil e brasileiros no exterior. São Carlos: EdUFSCar, Editora Sumaré, 2002.

PATARRA, Neide L.; BAENINGER, Rosana. Mobilidade espacial da população no Mercosul: metrópoles e fronteiras. Revista Brasileira de Ciências Sociais, São Paulo, v. 21, n. 60, fev. 2006.

PORTES, Alejandro. The New Second Generation. New York: Russel Sage Foundation, 1996.

PORTES, Alejandro; RUMBAUT, Rubén G. Legacies: the story of the immigrant second generation. California: University of California Press/Russell Sage Foundation, 2001. PORTES, Alejandro; ZHOU, M. The new second generation: segmented assimilation 
and its variants. In SUÁREZ-OROZCO, Marcelo; SUÁREZ-OROZCO, Carola; QIN, Desiree B. The new immigration: an interdisciplinary reader. New York: Taylor \& Francis Group, 2005.

PORTES, Alejandro; HALLEY, William; FERNANDEZ-KELLY, Patricia. Filhos de imigrantes nos Estados Unidos. Tempo Social, Revista de Sociologia da USP, v. 20, n. 1, São Paulo, 2008.

SILVA, Sidney A. Costurando sonhos: trajetória de um grupo de imigrantes bolivianos em São Paulo. São Paulo: Paulinas, 1997.

. Faces da latinidade: hispano-americanos em São Paulo. In Textos NEPO 55, Campinas/UNICAMP, 2008.

\section{Abstract}

\section{The second generation of Latin-Americans in the city of São Paulo and the issue of language}

Although São Paulo receives immigrants hailing from all over the world, we are able to observe an increase in arrivals of Latin-Americans, especially Bolivians, Paraguyans, and Peruvians, principally after the 1970s. LatinAmerican immigrants have constructed their lives in the city, establishing homes and forming families. Their children face the issue of being a part of the second generation, which can be defined as the collection of individuals born after the initial arrival of their parents into Brazil. Comprehending how the second generation has established itself in São Paulo through relationships maintained with local communities is fundamental to understanding the effects of immigration on society. Therefore, the study strives to explain the life and experiences of second generation LatinAmericans in São Paulo, highlighting the issue of language.

Keywords: second generation, international migration, language.

Recebido para publicação em 24/02/2014.

Aceito para publicação em 20/05/2014. Received for publication on February, 24 2013. Accepted for publication on May, 20 2013. 